\title{
(DE)REGULATING NEUROENHANCEMENT
}

Jasper L. Tran* \& Derek Tri Tran**

I. WHAT IS NEUROENHANCEMENT? ..........................................104

A. Definitions of Enhancement and Neuroenhancement ...........104

B. Where Are We with Neuroenhancement? ...........................107

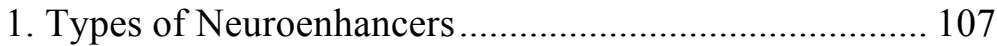

2. Safety of Neuroenhancers ................................................ 110

II. SELF-REgULATING NEUROENHANCEMENT ........................................112

A. The Fairness Problem .........................................................112

B. Self-Regulating Neuroenhancement................................... 114

C. Application to Three Case Studies .......................................119

1. In the Academic Settings.............................................. 119

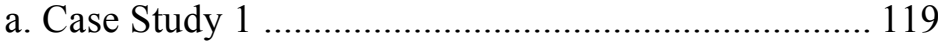

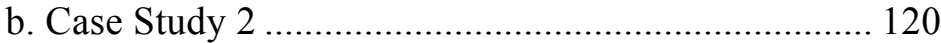

2. In the Employment Settings: Case Study 3 ................... 120

D. Rebuttals to Common Counterarguments Against Self-

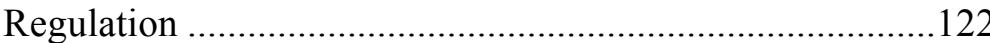

1. "Playing God," Unnatural and Human Integrity ............ 122

2. Discrimination and Systemic Coercion Remain ............ 123

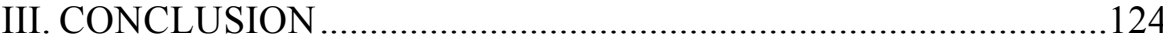

"Man is not going to wait passively for millions of years before evolution offers him a better brain." _-Corneliu E. Giurgea ${ }^{2}$

* Policy Fellow at University of Minnesota, former Google Policy Fellow at George Mason University. Sincere thanks to Francis X. Shen for commenting on earlier draft. Contact the authors at tran4lr@gmail.com. (C) Jasper L. Tran \& Derek Tri Tran.

** University of California, Merced.

1. M. Elizabeth Smith \& Martha J. Farah, Are Prescription Stimulants "Smart Pills"?: The Epidemiology and Cognitive Neuroscience of Prescription Stimulant Use by Normal Healthy Individuals, 137 Psychol. Bull. 717, 717 (2011) (citing Michael Gazzaniga, The Ethical Brain 71 (1st ed. 2005)).

2. Corneliu E. Giurgea (Jan. 6, 1923-Dec. 30, 1995) was a Romanian psychologist and chemist. In 1972, Giurgea coined the term "nootropic" after synthesizing Piracetam. 
Neuroenhancement ${ }^{3}$ is on the rise. ${ }^{4}$ Current available neuroenhancers include pharmaceutical stimulants like caffeine, Adderall, Ritalin, Provigil, beta blockers and the like. ${ }^{5}$ But what about nicotine and pain relievers - are they not neuroenhancers and if so, why not? ${ }^{6}$ As new neuroenhancing methods, such as neural implants, emerge, it becomes important to ask: what constitutes neuroenhancement?

Commentators disagree about what constitutes enhancement and neuroenhancement. Some distinguish enhancement from treatment and tools, although all involve some improvement around a "normal" person standard. However, one question remains central to defining neuroenhancement: what is a "normal" person?

A recent rise in abusing neuroenhancing pharmaceuticals without a prescription, ${ }^{7}$ especially in academic settings, ${ }^{8}$ has generated a lot of press coverage. ${ }^{9}$ Movies like Lucy ${ }^{10}$ and Limitless ${ }^{11}$ "predict[] a future

"Nootropics" refers to pharmaceutical stimulants that improve one or more aspects of mental function, such as working memory, motivation, and attention. See Gazzaniga, supra note 1 .

3. Also referred to as cognitive enhancement.

4. See, e.g., Henry Greely et al., Towards Responsible Use of Cognitive-Enhancing Drugs by the Healthy, 456 Nature 702, 702-05 (2008) [hereinafter Greely, Nature]; cf. Jasper L. Tran, The Law and 3D Printing, 31 J. Info. Tech. \& Privacy L. 505, 506-07 (2015) (discussing that the emerging field of law and 3D printing is on the rise). For a discussion on 3D printing, see generally Jasper L. Tran, To Bioprint or Not to Bioprint, 17 N.C. J.L. \& Tech. 123, 133-35 (2015).

5. See Kelline R. Linton, Comment, Scholastic Steroids: Is Generation Rx Cognitively Cheating?, 39 Pepp. L. Rev. 989, 995-1001 (2012) (discussing Adderall, Ritalin, Provigi1, and beta blockers). See generally Jasper L. Tran, Timing Matters: Prior Art's Age Infers Patent Nonobviousness, 50 Gonz. L. Rev. 189, 207-08 (2015) (discussing pharmaceutical litigation). For a discussion on patents, see Jasper L. Tran, Software Patents: A One-Year Review of Alice v. CLS Bank, 97 J. Pat. \& Trademark Off. Soc'y 532, 533-35 (2015).

6. See infra Part I.A.

7. See Linton, supra note 5, at 990-94. The emerging market of biosimilar and follow-on biologic make neuroenhancing pharmaceuticals more relevant than ever. See generally Vinita Banthia, Note, Biosimilar Regulation: Bringing the United States Up to Speed with Other Markets, 16 Minn. J.L. Sci. \& Tech. 879, 888-92 (2015).

8. See, e.g., Daniel Ari Kapner, Higher Ed. Ctr. for Alcohol \& Other Drug Prevention, Recreational Use of Ritalin on College Campuses (2003), available at http:// www.mtsu.edu/healthpro/documents/rec_use_of_ritalin.pdf; Christian J. Teter et al., Illicit Use of Specific Prescription Stimulants Among College Students: Prevalence, Motives, and Routes of Administration, 26 Pharmacotherapy 1501, 1501-10 (2006).

9. See, e.g., Roger Cohen, The Competition Drug, N.Y. Times (Mar. 4, 2013), http:// www.nytimes.com/2013/03/05/opinion/global/roger-cohen-adderall-the-academiccompetition-drug.html; Alan Schwarz, Risky Rise of the Good-Grade Pill, N.Y. Times, June 9, 2012, at A1, available at http://www.nytimes.com/2012/06/10/education/seekingacademic-edge-teenagers-abuse-stimulants.html.

10. Lucy (EuropaCorp et al. 2014) (after accidentally ingesting a mysterious drug, a woman transforms into a merciless warrior evolved beyond human logic). 
in which a smart pill allows one to achieve almost limitless learning and memory ability." 12 Whether and how regulations should be introduced to address neuroenhancement remain open to discussion.

A fairness problem raises accessibility concerns: some individuals have access to neuroenhancing pharmaceuticals while others do not. Furthermore, the fairness problem could lead to coercion when there is an unequal power dynamic, especially in the employment context. There is also discrimination against the non-enhanced or against the sick, disabled and unfortunate ones that are completely outside of enhancement. The fairness problem calls for a solution that guarantees accessibility to almost everyone to improve his/her cognitive functions.

This Article explores these questions, and proposes to allow each individual, either as an adult or as a parent of a minor, to self-regulate his/her or his/her children's use of neuroenhancing pharmaceuticals. Government efforts and funding should instead be focused on educating users on the side effects of neuroenhancers. There should be a strict prohibition against coercion and discrimination in the employment settings. With neuroenhancing internal devices, the FDA should defer to the medical professionals to determine whether an individual would benefit from such technology without much harm.

There are three main arguments for this proposal. First, this proposal would likely solve the current systemic unfairness problem and level the playing field for individuals not having access to neuroenhancing pharmaceuticals. Second, this proposal would likely promote individualism, which aligns well with our Constitution's guaranty of freedom. Third, this proposal would likely result in a positive net effect on the society at large, such as "smarter," less stressed and healthier people, more innovations, preserving healthcare resources, and ultimately benefiting the U.S. economy.

This Article proceeds in three parts. Part I defines enhancement and neuroenhancement, then describes different types of neuroenhancers and the safety of using neuroenhancers. Part II addresses the unfairness problem, discusses the proposal in detail, and applies such proposal to three illustrative case studies. Part II also rebuts some of the common counterarguments against this proposal. Part III concludes.

11. Limitless (Virgin Produced et al. 2011) (a struggling writer becomes a financial wizard by taking a mysterious pill that enables him to access $100 \%$ of his brain abilities).

12. Owen D. Jones et al., Law and Neuroscience 634 (1st ed. 2014); see also Smith \& Farah, supra note 1 (discussing "smart pills" used by normal healthy individuals). 


\section{WHAT IS NEUROENHANCEMENT?}

\section{A. Definitions of Enhancement and Neuroenhancement}

To understand neuroenhancement, it is important to start with defining enhancement. From the moment a baby is born, almost any action $\mathrm{s} / \mathrm{he}$ does that results in an improvement can be classified as an enhancement, i.e. an improvement from his/her previous self. For example, an individual can enhance crawling as a baby by learning how to walk or one's talking ability by reading more to improve his/her vocabulary. However this still begs the question, where do we draw the line to determine what constitutes enhancement?

Commentators disagree about what constitutes enhancement. The classic debate distinguishes enhancement from treatment. ${ }^{13}$ Some view enhancement as increasing one's ability from a neutral disposition ${ }^{14}$ to a positive disposition. For example, Oxford University's Professor Nick Bostrom defines enhancement as "an intervention that improves a subsystem in some way other than repairing something that is broken or remedying a specific dysfunction." "15 But to determine whether something is broken, one would need to identify its default or normal state. However, it is often difficult to define what "normal" is, when not many things have a clear-cut line. One universal example of a clear-cut "normal" is 20/20 in vision, where any deviation from $20 / 20$ is considered "impaired." When it comes to other situations, not so much.

Stanford Law Professor Henry T. Greely takes enhancement a step further-he defines enhancement as "a change to the human body that we do intentionally for the purpose not of making the disabled or the sick normal, healthy, or well, but of making healthy people better than well or of making disabled people not just normal, but beyond normal."17 Greely's definition expands on Bostrom's definition. Greely's

13. Some also use the term "therapy" instead of "treatment." See, e.g., President's Council on Bioethics, Beyond Therapy: Biotechnology and the Pursuit of Happiness 13-16 (2003).

14. The neutral position is defined by a person possessing normal abilities and no deficiency. But then the question becomes: how do we define "normal?"

15. Nick Bostrom \& Anders Sandberg, Cognitive Enhancement: Methods, Ethics, Regulatory Challenges, 15 Sci. Eng. Ethics 311, 312 (2009); see also Smith \& Farah, supra note 1, at 717 (“'[S]mart pill' is a drug that increases the cognitive ability of anyone taking it, whether the user is cognitively impaired or normal.").

16. See Jonathan Brown, Defining Disability in 2001: A Lower Court Odyssey, 23 Whittier L. Rev. 355, 364 (2001).

17. Henry T. Greely, Remarks on Human Biological Enhancement, 56 U. Kan. L. Rev. 1139, 1140 (2008) [hereinafter Greely, Remarks]. 
definition also includes from a negative position to a positive position, ${ }^{18}$ but not an increase from a negative position to a neutral position or a negative position to a less-negative-but-not-yet-neutral position. Essentially, both Bostrom and Greely's definitions try to avoid including treatment, i.e. from a negative position to a neutral position. However, one important question remains - how to define "normal" in both of Bostrom and Greely's definitions.

Arguendo, can enhancement encompass treatment? Most people do not think so because they would not classify an individual from negative position to a neutral position or a negative position to a lessnegative-but-not-yet-neutral position after receiving a treatment as an "enhanced" individual. ${ }^{19}$ Plus, there must have been a reason why there are two words in the dictionary for enhancement and treatment, ${ }^{20}$ and they are not synonyms. ${ }^{21}$ But then there is a problem with defining treatment-there are two situations of treatment: (1) clear-cut treatments that successfully treated "sub-normal" individuals back to a "normal" position where "normal" is clear, e.g. having eyesight of 20/ 20 , and (2) "ambiguous" treatments, which "normal" is not so clear, e.g. some individual with mild attention deficit hyperactivity disorder (ADHD) can take Adderall and become "better" than an average individual in term of learning ability.

Others further distinguish enhancement (as "selves") from tools. ${ }^{22}$ They argue that tools are not parts of "selves" because tools lack permanence (i.e. they are temporary), and can be removable. ${ }^{23}$ For example, $\operatorname{LASIK}^{24}$ is permanent whereas glasses are removable, ${ }^{25}$ although

18. Greely's definition presumes that the negative position passed the neutral position into the positive position.

19. See, e.g., Bostrom \& Sandberg, supra note 15; Greely, supra note 17.

20. See Merriam Webster's Collegiate Dictionary 276, 859 (10th ed. 1993) [hereinafter Dictionary].

21. See id.

22. See Henry T. Greely, Regulating Human Biological Enhancements: Questionable Justifications and International Complications, 4 Santa Clara J. Int'1 L. 87, 94-96 (2005) [hereinafter Greely, Regulating].

23. See id. Some tools can also be turned on or off. See id. at 94.

24. LASIK, an acronym for "laser in-situ keratomileusis"-commonly referred to as laser eye surgery or laser vision correction-is a refractive surgery to correct myopia, hypermetropia, and astigmatism. See generally D.R. Sanders \& J.A. Vukich, Comparison of Implantable Contact Lens and Laser Assisted in situ Keratomileusis for Moderate to High Myopia, 22 Cornea 324, 324-31 (2003); James O'Reilly, Essay, An Eye for an Eye: Foresight on Remedies for LASIK Surgery's Problems, 71 U. Cin. L. Rev. 541, 542-44 (2003).

25. But see Greely, Regulating, supra note 22, at 95 ("Eyeglasses have been part of my life for over forty years. Although I do take them off to sleep, to shower, or to swim, they seem more a part of me than, say, my useless toe. They seem more a part of me than various internal, unperceived and largely unknown organs, such as my appendix or my spleen.”). 
both would improve an individual's vision. ${ }^{26}$ Should one of these things count as enhancement whereas the others - such as tools and treatment- do not, although all result in some sort of improvement?

To fully cover neuroenhancement, this Article adopts the broader view of enhancement - any improvement, including tools and "ambiguous" treatment (as defined above) but not clear treatment, constitutes enhancement. Note that this aligns with Greely's definition of enhancement, although Greely did not clearly distinguish between a clearcut treatment and an ambiguous treatment. ${ }^{27}$ Neuroenhancement would be then defined, according to Greely's definition, as "a change to the [human brain] that we do intentionally for the purpose not of making the disabled normal or well, but of making normal people better than well or of making disabled people not just normal, but beyond normal." 28 That includes any improvement of an individual's cognitive function, excluding clear-cut neuroscience treatment. Some example of clear-cut neuroscience treatments in neuroenhancement are helping people with Posttraumatic Stress Disorder (PTSD) to recover, ${ }^{29}$ or restoring the memory of people with Alzheimer's disease. ${ }^{30}$

Greely further provides six concerns about human biological enhancement: safety, fairness, coercion, integrity, long-term social effects and unnatural enhancement. ${ }^{31}$ Specifically for neuroenhancement, the safety, fairness and coercion concerns are worth investigating. ${ }^{32}$

26. See generally, O'Reilly, supra note 24 .

27. See Greely, Remarks, supra note 17 , at 1140

28. See id. (defining enhancement using the same quoted language).

29. See, e.g., Jeneen Interlandi, A Revolutionary Approach to Treating PTSD, N.Y. Times Sunday Magazine, May 22, 2014, at MM42, available at http://www.nytimes.com/ 2014/05/25/magazine/a-revolutionary-approach-to-treating-ptsd.html?_r=0. For a discussion on PSTD, see generally Am. Psychiatric Ass'n, Diagnostic and Statistical Manual of Mental Disorders 271-80 (5th ed. 2013).

30. See, e.g., Madeleine Acey, Brain Implants: Restoring Memory with a Microchip, CNN (May 8, 2013 6:26 PM), http://www.cnn.com/2013/05/07/tech/brain-memoryimplants-humans/ [hereinafter Acey, Brain Implants] (discussing the possibility of using a brain implant to restore memory in people with Alzheimer's disease). For a discussion on Alzheimer's disease, see generally Alistair Burns \& Steve Iliffe, Alzheimer's Disease, 338 BMJ b158, b158 (2009).

31. Greely, Remarks, supra note 17, at 1148-54.

32. This aligns with Greely's thinking that only three concerns - safety, fairness, and coercions - are justified, relevant and appropriate. Henry T. Greely, Enhancing Brains: What Are We Afraid Of?, Cerebrum (July 14, 2010) [hereinafter Greely, Enhancing], http:// www.ncbi.nlm.nih.gov/pmc/articles/PMC3574770/; Greely, Remarks, supra note 17, at 1148. 


\section{B. Where Are We with Neuroenhancement?}

\section{Types of Neuroenhancers}

Neuroenhancement can take many shapes or forms. ${ }^{33}$ Studying is the most basic form of neuroenhancement. Learning a new skill can also be viewed as a type of neuroenhancement. However, the more interesting type of neuroenhancement is pharmaceutical neuroenhancerswhich is what most people think of when they hear "neuroenhancement." 34

"Many of the medications used to treat psychiatric and neurological conditions also improve the performance of the healthy." 35 Most people view pharmaceutical stimulants like caffeine, Adderall, Ritalin, Provigil, beta blockers, and the like as neuroenhancers because they improve cognitive functions, such as the ability to focus for a long period of time. ${ }^{36}$ Some people also view future technological tools like neural implants in neuroengineering as neuroenhancement. ${ }^{37}$ Yet, people tend to exclude nicotine and painkillers as neuroenhancers. ${ }^{38}$ To the contrary, this Article argues that nicotine, but not painkillers, should be classified as neuroenhancers as well.

Neuroenhancing pharmaceuticals vary in administration methods and addiction potentials due to their differences in affecting the brain circuitry. ${ }^{39}$ Nonetheless, the United States (U.S.) Food and Drug Administration (FDA $)^{40}$ approves neuroenhancing pharmaceuticals for particular medicinal purposes, yet does not acknowledge their neuroen-

33. Cf. Felix Duecker, Tom A. de Graaf, \& Alexander T. Sack, Thinking Caps for Everyone? The Role of Neuro-Enhancement by Non-Invasive Brain Stimulation in Neuroscience and Beyond, 8 Frontier Sys. Neuroscience 71 (2014) (outlining various forms neuroenhancement can take).

34. See, e.g., MJ Hyland, The Drugs do Work: My Life on Brain Enhancers, The Guardian (May 3, 2013 6:00 PM EDT), http://www.theguardian.com/lifeandstyle/2013/ may/03/brain-enhancing-drugs-mj-hyland; cf. Smith \& Farah, supra note 1 (discussing prescription stimulants as "smart pills").

35. Greely, Nature, supra note 4, at 702 .

36. See Linton, supra note 5, at 995-1001.

37. See, e.g., Acey, Brain Implants, supra note 30

38. Yet, some have considered nicotine as treatment. See, e.g., Tabitha M Powledge, Nicotine as Therapy, 2 Pub. Libr. Sci. Biology e404, e404 (2004).

39. Linton, supra note 5 , at 1001 .

40. "The FDA, a federal administrative agency within the Department of Health and Human Services, is responsible for protecting and promoting public health by ensuring that drugs and medical devices are safe and effective." Lisa M. Mottes, Comment, The Need for Federal Preemption of State Tort Claims in the Context of "New Drugs" and PremarketApproved Medical Devices, 41 Seton Hall L. Rev. 723, 723-24 (2011). See generally 21 U.S.C. § 393 (2011). 
hancement uses. $^{41}$ "Adderall, Ritalin, and Provigil are federallyspecified schedule drugs, or federally controlled substances, because they can encourage abuse or dependence." ${ }^{42}$ Conversely, caffeine and beta blockers are not federally regulated yet because they are generally not addictive. ${ }^{43}$ Recently, the FDA has started investigating caffeine's safety, especially its effects in children and adolescents. ${ }^{44}$

On the other hand, taking nicotine ${ }^{45}$ and pain medication ${ }^{46}$ can dampen one's feelings and moods. ${ }^{47}$ Most people associate this effect with bringing an individual from a negative position to a neutral position, ${ }^{48}$ thus, not an enhancement. ${ }^{49}$ However, an individual might be able to study or work for about 2 more hours by smoking a cigarette. ${ }^{50}$ This may vary for different individual users, but it raises interesting questions about pharmaceutical neuroenhancer's effects. Furthermore, an individual with chronic pain can get through his/her day by taking

41. Linton, supra note 5 , at 1001 .

42. Id. at 1013 .

43. Id. at 1000; Sally Satel, Is Caffeine Addictive?-A Review of the Literature, 32 Am. J. Drug Alcohol Abuse 493, 493-502 (2006). But see Sandra Blakeslee, Yes, People Are Right. Caffeine Is Addictive, N.Y. Times (Oct. 5, 1994), http://www.nytimes.com/ 1994/10/05/us/yes-people-are-right-caffeine-is-addictive.html.

44. Press Release, U.S. Food \& Drug Admin., FDA Deputy Commissioner for Foods and Veterinary Medicine Michael R. Taylor's Statement on the Institute of Medicine Report on Caffeine in Food and Dietary Supplements (Jan. 17, 2014), available at http:// www.fda.gov/NewsEvents/Newsroom/PressAnnouncements/ucm382203.htm ("[W]e continue our investigation of the safety of caffeine, particularly its effects on children and adolescents.").

45. Nicotine is commercially available in cigarette or tobacco chews. See generally Jack Jacob Gottsegen, Tobacco: A Study of Its Consumption in the United States 107 (1940).

46. Commonly referred to as painkillers.

47. See, e.g., Patrick Zickler, Nicotine's Multiple Effects on the Brain's Reward System Drive Addiction, 17 Nat'l Inst. Drug Abuse Notes 1 (March 2003), available at http:// archives.drugabuse.gov/NIDA_Notes/NNVol17N6/Nicotine.html (discussing that nicotine stimulates dopamine-releasing cells directly by stimulating their acetylcholine receptors, and indirectly by triggering higher levels of glutamate); Doug Lisle, How to Feel Better Fast, TrueNorth Health Ctr. (May 30, 2010 9:11 AM), http://www.healthpromoting.com/learningcenter/articles/how-feel-better-fast.

48. This is like the definition of treatment, but for an individual's temporary mood and feelings instead of injury. See Dictionary, supra note 20, at 859 (defining the plain meaning of "treatment"); supra Part I.A

49. This is the author's own observation. But see Nadia Chaudhri et al., SelfAdministered and Noncontingent Nicotine Enhance Reinforced Operant Responding in Rats: Impact of Nicotine Dose and Reinforcement Schedule, 190 Psychopharmacology 353, 353-62 (2007); Daniel S. McGehee et al., Nicotine Enhancement of Fast Excitatory Synaptic Transmission in CNS by Presynaptic Receptors, 269 Sci. 1692, 1692-96 (1995).

50. This is the author's anecdotal experience with nicotine. 
pain medication but cannot without. ${ }^{51}$ Interestingly, some even claim drinking a glass of wine ${ }^{52}$ helps them study better than not drinking any ${ }^{53}$ although alcohol is a depressant rather than a stimulant. ${ }^{54}$ Why are nicotine and painkillers then not neuroenhancers? Probably because most people see nicotine and painkillers are more like treatment than enhancement, but nicotine is not viewed as a type of treatment-rather nicotine is more for recreational uses ${ }^{55}$ - whereas painkillers are viewed as a clear-cut treatment. Because this Article takes a broader view of enhancement including ambiguous treatment, nicotine is considered a neuroenhancer, whereas painkillers are not.

Though both pharmaceutical neuroenhancers and neural implants are types of neuroenhancement, this Article distinguishes them under the FDA's definitions of drug and device. The FDA defines a "drug" as "articles intended for use in the diagnosis, cure, mitigation, treatment, or prevention of disease in man or other animals; and articles (other than food) intended to affect the structure or any function of the body of man or other animals." " The FDA defines a "device" as "an instrument, apparatus, implement, machine, contrivance, implant, in vitro reagent, or other similar or related article, including any component, part, or accessory," but it "does not achieve its primary intended purposes through chemical action within or on the body of man or other animals and which is not dependent upon being metabolized for the achievement of its primary intended purposes." ${ }^{, 57}$ Essentially, a neuroenhancing device

51. See Important Facts About Non-Narcotic Pain Drugs, Health, http:// www.health.com/health/condition-article/0,,20189476,00.html (last updated April 06, 2008) ("A third of Americans over 65 use nonsteroidal anti-inflammatory drugs (NSAIDs) every day, according to the American Pain Foundation"). But see Andy Steiner, Chronic Pain Sufferers Find Prescription Painkillers Ineffective for Long-term Relief, Survey Reports, Minn Post (Oct. 31, 2014), http://www.minnpost.com/mental-health-addiction/2014/10/chronicpain-sufferers-find-prescription-painkillers-ineffective-lon (explaining a recent survey that found Americans do not find long term relief for chronic pain from the use of prescription drugs).

52. Wine contains alcohol, which is the common name for the chemical ethanol. See Duncan Baird Douglass, Note, Constitutional Crossroads: Reconciling the Twenty-First Amendment and the Commerce Clause to Evaluate State Regulation of Interstate Commerce in Aloholic Beverages, 49 Duke L.J. 1619, 1619 n.1 (2000).

53. See, e.g., Brian E. Bernier, et al., Previous Ethanol Experience Enhances Synaptic Plasticity of NMDA Receptors in the Ventral Tegmental Area, 31 J. Neuroscience 5205, 5205-12 (2011) (claiming that alcohol helps the brain remember better).

54. See, e.g., Tina Wescott Cafaro, Slipping Through the Cracks: Why Can't We Stop Drugged Driving?, 32 W. New Eng. L. Rev. 33, 47 n.65 (2010).

55. See, e.g., George P. Smith, II, Cigarette Smoking As A Public Health Hazard: Crafting Common Law and Legislative Strategies for Abatement, 11 Mich. St. U. J. Med. \& L. 251, 281 (2007).

56. 21 U.S.C. $\S 321(\mathrm{~g})(1)(2009)$.

57. 21 U.S.C. $§ 321(\mathrm{~h})(2009)$. 
is a tool with neuroenhancement effect, but is also removable and not ingestible. ${ }^{58}$ Neuroenhancing devices can be further broken down to internal (e.g. neural implant ${ }^{59}$ ) or external (e.g. Google glasses ${ }^{60}$ ).

\section{Safety of Neuroenhancers}

One feature of neuroenhancement is that it does not pass in any direct biological way to the next generation, ${ }^{61}$ thus, allowing each individual to solely benefit from neuroenhancement without affecting his/ her offspring. Furthermore, most drugs can be beneficial, if taken in moderation. ${ }^{62}$ No matter how beneficial they are, most drugs become poison when in excess. ${ }^{63}$

Regular usage of Adderall, Ritalin, and Provigil comes with strong addictions,${ }^{64}$ whereas regular use of caffeine, beta blockers, and nicotine do not. ${ }^{65}$ This reason alone prompts the FDA to federally regulate the former group but not the latter. ${ }^{66}$ It is believed that "[e]verybody can become tolerant and dependent to a medication., ${ }^{, 67}$ Furthermore, some

58. See supra Part I.A (discussing the distinction of enhancement vs. tools).

59. See, e.g., Acey, Brain Implants, supra note 30

60. See generally Kristin Bergman, Cyborgs in the Courtroom: The Use of Google Glass Recordings in Litigation, 20 Rich. J.L. \& Tech. 11, 15-16 (2014); Jeff Tang, Beginning Google Glass Development (2014); Michael S. Wagner, Google Glass: A Preemptive Look at Privacy Concerns, 11 J. Telecomm. \& High Tech. L. 477, 485-87 (2013).

61. Henry T. Greely, Neuroethics and Elsi: Similarities and Differences, 7 Minn. J.L. Sci. \& Tech. 599, 629 (2006) [hereinafter Greely, Neuroethics] ("Neuroscience enhancement will not pass in any direct biological way from one generation to the next.").

62. See, e.g., Lucy Sherriff, Drugs Are Fine In Moderation, Say UEA Students, Huffington Post UK (Aug. 1, 2013 16:46 GMT), http://www.huffingtonpost.co.uk/2013/01/08/ drugs-are-fine-in-moderation-uea-students_n_2432458.html. However, most people recognize that drugs can still have bad side-effects even if taken in moderation.

63. See Center for Disease Control and Prevention, Unintentional Drug Poisoning in the United States 1 (July 2010), available at http://www.cdc.gov/homeandrecreationalsafety/ pdf/poison-issue-brief.pdf. Some examples of drugs that do not become poison when consumed in excess are vitamins $\mathrm{B}$ and $\mathrm{C}$, where human urinates out the excess consumption. See, e.g., Gavin King et al., Rate of Excretion of Vitamin C in Human Urine, 17 Age 87, 87-92 (1994).

64. Linton, supra note 5, at 1013 ("Adderall, Ritalin, and Provigil . . can encourage abuse or dependence.").

65. See, e.g., id. at 1000 ("[B]eta blockers are generally not addictive.").

66. See id at 1013. ("Adderall, Ritalin, and Provigil are federally-specified schedule drugs, or federally controlled substances, because they can encourage abuse or dependence").

67. Miranda Hitti, Prescription Painkiller Addiction: 7 Myths, WebMD, http:// www.webmd.com/pain-management/features/prescription-painkiller-addiction-7-myths (citing Christopher Gharibo, MD, Director of Pain Medicine at the NYU Langone Medical School and NYU Hospital for Joint Diseases). Note that this Article does not discuss the distinction between addiction and dependence. 
claim that caffeine, beta blockers, and nicotine can be addictive. ${ }^{68}$ Yet, the FDA plays its paternalism role on Adderall, Ritalin, and Provigil but not caffeine, beta blockers, and nicotine. Interestingly, although all of the listed neuroenhancing pharmaceuticals can be abused in one way or another, the FDA arbitrarily drew the line to regulate some neuroenhancing pharmaceuticals, but not others, based on its own abuse potential guideline. ${ }^{69}$

There are few, if any, good studies of the safety and efficacy of pharmaceutical neuroenhancers when students use them without a prescription to improve their grades. ${ }^{70}$ Yet, a 2008 survey showed that 4\% of 1,800 randomly surveyed college students had prescriptions for Adderall or Ritalin and another $34 \%$ of the students (with more than half of the juniors and seniors) had used the drugs without a prescription, almost all of whom said they took it to "help them study." 11

Moreover, "off-label use" is when a physician may legally prescribe a new drug, biologic, or medical device for any use, even though that use may never have been proven safe or effective. " "[A]s far as the FDA is concerned, approved drugs, biologics, and devices can be used for enhancement purposes where neither the safety nor the efficacy is known and where the balance of benefit and risk may be quite different." ${ }^{73}$ Yet, the FDA trusts doctors to know best for each individual by giving them the power to write prescription-for both treatment and off-label uses ${ }^{74}$ - rather than respecting each individual's choice and allowing him/her to decide what is best for himself/herself, such as talk-

68. See Blakeslee, supra note 43 (discussing that caffeine is addictive); Zickler, supra note 47 (discussing that nicotine is addictive). Painkillers can also be addictive. Hitti, supra note 67 (discussing prescription painkillers' addiction).

69. See Linton, supra note 5, at 1001, 1013. For a discussion of drugs' abuse potential, see generally Food \& Drug Admin., Draft Guidance for Industry on Assessment of Abuse Potential of Drugs; Availability, 75 Fed. Reg. 4400 (Jan. 21, 2010).

70. Greely, Enhancing, supra note 32, at 4.

71. See Alan D. DeSantis et al., Illicit Use of Prescription ADHD Medications on a College Campus: A Multimethodological Approach, 57 J. Am. C. Health 315, 315-23 (2008). This study raises an interesting question of what it means to "help them study." Is it simply just some improved focus? Or do the methamphetamine effects allow one to studying all night, etc.?

72. Greely, Enhancing, supra note 32, at 4.

73. Id.

74. Cf. Claire Foster, The Ethics of Medical Research on Humans 9 (2001) ("[The patients'] doctor has their best interest at heart."). Doctors can write prescription for treatment, but some ambiguous treatment helps one cross the "normal" person's standard to be more "enhanced." 
ing neuroenhancing pharmaceuticals. ${ }^{75}$ Proponents of individualism would disagree with the FDA, arguing "the right of individuals to selfdetermination" is not being honored. ${ }^{76}$

\section{Self-Regulating NeUROENHANCEMENT}

This Part proposes a solution to the fairness problem. Subsection A first describes the fairness problem. Subsection B goes into details describing the specific proposal. Subsection $C$ applies the proposal to three case studies discussing neuroenhancers' use in the academic and employment settings. Subsection D then rebuts some of the common counterarguments against this proposal.

\section{A. The Fairness Problem}

Starting with enhancement in competitive sports pertaining to "weightlifters, wrestlers, or bodybuilders, and the football players who are trying to make it to the NFL[, it can be unfair] when one competitor is using enhancing drugs but the others are not[.]",77

Assume neuroenhancing pharmaceuticals work, in the academic settings, it can be unfair for one student to take an exam after studying all night ${ }^{78}$ using Adderall, or taking many double espressos or energy drinks to help stay up, when another student has not taken any neuroenhancing pharmaceuticals. ${ }^{79}$ A recent surge of Adderall sales to college students without a diagnosed mental disorder or prescription to gain an academic advantage over others shows the relevance of this unfairness concern. ${ }^{80}$ It can also be unfair when a student who can afford an expensive neurologist to write a prescription of Adderall for off-label uses, ${ }^{81}$ does substantially better on all aspects of academics compared to before taking Adderall, when other students cannot afford to do so. It can be unfair for a student to be allergic to caffeine, thus, does not drink any coffee or energy drink while studying, when other students are not allergic to caffeine and constantly drink coffee to study.

75. Cf. Stacy L. Mojica \& Dan S. Murrell, The Right to Choose-When Should Death Be in the Individual's Hands?, 12 Whittier L. Rev. 471 (1991) (discussing the right to choose to commit suicide).

76. See Foster, supra note 74, at 9 (2001).

77. Greely, Remarks, supra note 17 , at 1151 .

78. Commonly referred to as "pulling an all-nighter."

79. Greely, Enhancing, supra note 32, at 5.

80. See, e.g., Schwarz, supra note 8 .

81. "Off-label use" is when a physician may legally prescribe a new drug, biologic, or medical device for any use, even though that use may never have been proven safe or effective. Greely, Enhancing, supra note 32, at 4. 
Furthermore, it can be unfair for one student to take an exam after being tutored when another could not afford the tutor, or similarly after using a computer that the other could not afford. ${ }^{82}$ It can be unfair for a child to attend a boarding school then get into an Ivy League college, as compared to another child who attend a public school then register for a local college. In the society at large, it can be generally unfair if only the rich or only certain groups obtain access to these types of neuroenhancers and others do not. ${ }^{83}$

The unfairness problem aims at the systemic unfairness inherent in the regulation of neuroenhancing pharmaceuticals, rather than each individual's conscious choice that leads to an unfair result. For example, the unfairness problem does not include the scenario where a student could get a good night of sleep while another student could not because $\mathrm{s} /$ he was busy at soccer practice all night. One might counter argue that the second student chooses (or his/her parents choose for him/her) to be at soccer practice instead of sleeping - the reality is that this individual made a choice and suffers the potential consequences of not sleeping before an exam. The systemic unfairness problem does not include an individual's choice that potentially leads to consequences.

The fairness problem can cause coercion when there is an unequal power dynamic between two parties. In the military, "[m]ilitary physicians, citing the dangers of sleep-restricted environments, claim an obligation to 'help healthy individuals optimize their cognitive potential.", 84 The military might force soldiers to take these alertness-improving pills or else court-martial them. ${ }^{85}$

In the employment context, "[e]mployers often force employees to attend workshops or take courses to improve the employees' performance, without any real evidence that such interventions are either safe or effective." ${ }^{86}$ An employer could simply force its employees to take these memory-improving pills or else fire them. ${ }^{87}$ An employer might want its employees to have increased concentration and productivity in

82. Id. at 5 .

83. Greely, Remarks, supra note 17, at 1151-52.

84. Stephanie A. Kostiuk, Note, After GINA, NINA? Neuroscience-Based Discrimination in the Workplace, 65 Vand. L. Rev. 933, 975-76 (2012).

85. See Greely, Enhancing, supra note 32, at 6 ("Should the military be able to say, 'Take these alertness-improving pills or you will be court-martialed?"'). For a discussion on military enhancement issues, see generally Catherine L. Annas \& George J. Annas, Enhancing the Fighting Force: Medical Research on American Soldiers, 25 J. Contemp. Health L. \& Pol'y 283 (2009).

86. Greely, Enhancing, supra note 32, at 6 .

87. See id. ("[s]hould an employer be allowed to say, "Take these memory-improving pills or you will be fired'?”). 
a fixed duration or to work more hours by forcing its employees to take neuroenhancement, especially the acceptable forms of neuroenhancement such as caffeine or nicotine. An employer might also force an individual with ADHD to take Adderall to compete with an individual without ADHD in terms of his/her ability to focus. This situation shows that some employers can discriminate against individuals with ADHD. Generally, the flip side of coercion in the employment settings is "discrimination against the non-enhanced or against those who are completely outside of enhancement: the sick, disabled and unfortunate., ${ }^{\prime 88}$ Discrimination could be a result of unfairness in the first place. ${ }^{89}$

In summary, the systemic fairness problem can be distilled into accessibility - how some individuals gain an unfair advantage by having access to some sort of neuroenhancement while others do not. Such inequality can be caused, for example, by socioeconomics (affordability) or by genetics (allergy). The fairness problem calls for a solution that guarantees accessibility to almost everyone to improve his/her cognitive functions. This solution should also address the issues of coercion and discrimination.

\section{B. Self-Regulating Neuroenhancement}

The recent rise in abusing pharmaceutical stimulants without prescription, especially in academic settings, has called attention to the questions of whether and how regulations should be introduced to ad-

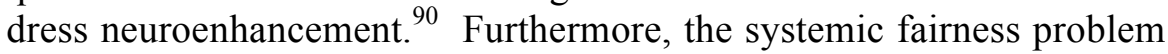
raises concerns such as some individuals having access to neuroenhancing pharmaceuticals when others do not. Moreover, the fairness problem can cause issues of coercion and discrimination when there is an unequal power dynamic between parties, especially in the employment context. The fairness problem calls for a solution that guarantees accessibility to almost everyone to improve his/her cognitive functions.

Some possible solutions are (1) to prohibit neuroenhancers altogether, ${ }^{91}(2)$ to instate stricter regulation upstream from either the FDA or each institution such as colleges and private employers, (3) to have

88. Greely, Remarks, supra note 17, at 1153; see also Kostiuk, supra note 92 (discussing workplace discrimination stemmed from neuroscience).

89. Cf. Making the Test for Unfair Discrimination More "Fair": A Proposal, 58 Bus. Law. 83 (2002) (discussing unfair discrimination in bankruptcy law).

90. See supra Introduction.

91. See also Greely, Enhancing, supra note 32, at 5 ("If limited access to effective cognitive enhancement is a problem, we probably could manage it much better by making enhancements available to everyone than by trying, probably unsuccessfully, to prohibit them to anyone."). 
no regulation whatsoever, or (4) to come up with a more creative regulation than what we have now. An example of a creative regulation could be that "teachers could institute different grading curves for "enhanced' and 'unenhanced' students." 92 However, this solution assumes all individual users would be honest about their neuroenhancer usages. Unfortunately, this solution would unlikely work because there is no incentive for an individual to come out and say s/he uses neuroenhancers, but instead, s/he would most likely stay silent and compete with the non-enhancing users in an unleveled playing field.

Because Adderall usage is prevalent on college campuses and students will likely continue to use Adderall whether it is regulated or not, ${ }^{93}$ instead of no regulation whatsoever (like the above solution (3)), this Article proposes to allow each individual, either as an adult or as a parent of a minor, to self-regulate his/her or his/her children's use of neuroenhancing pharmaceuticals. ${ }^{94}$ This proposal does not imply, for example, a 12-year-old child could walk into a pharmacy and purchase Adderall to use in his/her middle school. However, someone who is 18years-old or older should be able to purchase and use neuroenhancing pharmaceuticals at his/her own choice. In the case of a minor child, parents can be in charge of regulating their children's usage. ${ }^{95}$ Government efforts and funding should instead be focused on educating users on the side effects of neuroenhancers. ${ }^{96}$

To prevent coercion and discrimination in the employment settings, there should be a strict prohibition against coercion and discrimination - mostly in mental disability discrimination - in the employment settings. For example, a change in discrimination law can be allowing a plaintiff to establish a prima facie case of mental disability discrimination against an employer by proving that an employer did not hire an employee with a higher billable hours simply because of his/her mental disability.

92. Id.

93. Cf. Teter, supra note 8 , at 256 (discussing the motives for illicit use of prescription stimulants were to "(1) help with concentration, (2) increase alertness, and (3) provide a high").

94. See also Greely, Enhancing, supra note 32, at 5.

95. This proposal took into account of parents that allow their kids to abuse neuroenhancing pharmaceuticals to, for example, get into a better college. However, how parents raise their kids (within limits of course) is within their constitutional right. See, e.g., Donald C. Hubin, Parental Rights and Due Process, 1 J. L. \& Fam. Stud. 123 (1999).

96. Cf. George R. Gooch et. al., The Moral from Sorrell: Educate, Don't Legislate, 23 Health Matrix 237, 277 (2013) (arguing to educate, not legislate, when it comes to pharmaceuticals). 
With the special case of neuroenhancing internal devices such as neural implants, the FDA should defer to the medical professionals to determine whether an individual would benefit from such technology without much harm. Such regulation would be similar to current regulation on prescriptions for ADHD individuals. Because these internal devices are still technologies of the future, which may or may not become the reality later, we do not need to worry about regulating them as of now.

There are three main arguments for this proposal. First, the most immediate effect of allowing self-regulation of, i.e. universal access, to neuroenhancing pharmaceuticals would likely solve the systemic unfairness problem ${ }^{97}$ and level the playing field. ${ }^{98}$ Recall the root of the systemic unfairness problem is accessibility, ${ }^{99}$ thus, universal access to neuroenhancing pharmaceuticals would likely solve the systemic unfairness problem.

Second, this proposal would likely promote individualism and align with our Constitution's guaranty of freedom. This argument mirrors the classical debate between individualism vs. paternalism. In paternalism, individual choices are left to the government because the government supposedly knows what is best for its citizens, whereas in individualism each individual has a choice and can make his/her own decisions. ${ }^{100}$

The Constitution guarantees our freedoms and rights. Though our rights have limitations, a right to bodily autonomy ${ }^{101}$ is inherent within the right to privacy, ${ }^{102}$ which is derived from the concept of substantive due process, which stems from the Fifth and Fourteenth Amendments. ${ }^{103}$ The right to voluntarily take neuroenhancing pharmaceuticals is arguably within the right to bodily autonomy, as long as an individual does not overdose on neuroenhancing pharmaceuticals to commit sui-

97. See Greely, Enhancing, supra note 32, at 5 ("Cognitive enhancements need not lead to unfairness.").

98. See Id. at 5; supra Parts I.B.2 \& II.A.

99. See supra Part II.A.

100. Cf. Thad Brady, Note, Paternalism vs. Patient Autonomy: Is the FDA's "Mothering" Smothering Grandma's and Grandpa's Choice of Prescription Drug, 14 Elder L.J. 393 (2006) (discussing paternalism v. patient autonomy in FDA's regulation of prescription drug for elders).

101. The right to bodily autonomy is the right to do what we want with our body. See Marc Jonathan Blitz, Freedom of Thought for the Extended Mind: Cognitive Enhancement and the Constitution, 2010 Wis. L. Rev. 1049, 1094-98 (2010).

102. See Samuel D. Warren \& Louis Brandeis, The Right to Privacy, 4 Harv. L. Rev. 193 (1890); cf. Francis X. Shen, Neuroscience, Mental Privacy, and the Law, 36 Harv. J.L. \& Pub. Pol'y 653, 692-707 (2013) (discussing the right to mental privacy).

103. U.S. Const. amends. V \& XIV (“life, liberty, or property"). 
cide. ${ }^{104}$ One scholar further argues that neuroenhancement is protected by the freedom of thought. ${ }^{105}$ At the very least, this proposal would likely send the message that that the U.S. government still has faith and trusts each individual to make the right choice for himself/herself.

Third, this proposal will likely result in positive net effects on our society. Allowing self-regulation of neuroenhancement might lead to more individuals taking neuroenhancers. If so, our society would benefit overall. Enhancing humans cognitively would likely enhance human intelligence. The net effects of neuroenhancement on our society at large would result in "smarter" people because everything they do, including focusing and retaining memory, is likely better. Smarter people would likely work smarter, thus, could afford to work less and relax more, or if they choose so, work more and contribute more to our society. This would likely bleed into encouraging more innovation and technological advancements resulting in an overall positive feedback loop for our society.

Smarter people who could afford to work less and actually work less would likely be less stressed. Less stress helps with health overall, ${ }^{106}$ notwithstanding the counterargument of taking neuroenhancers might "mess up" one's body. Better health would likely lead to a longer lifespan. ${ }^{107}$ On a large scale, better health for most people would likely free up physicians' time to devote to other research and primary care areas, thus, preserving healthcare resources overall. ${ }^{108}$

Allowing universal access to neuroenhancing pharmaceuticals would ultimately help the U.S. economy. ${ }^{109}$ The black market for Adderall and other neuroenhancing drugs, where the government could not tax for these underground transactions, ${ }^{110}$ would consequently subside.

104. Because committing suicide is an unwritten common law crime. See, e.g., Wackwitz v. Roy, 418 S.E.2d 861 (Va. 1992). Furthermore, assisting suicide is a felony in all 50 states. See Catherine D. Shaffer, Note, Criminal Liability for Assisting Suicide, 86 Colum. L. Rev. 348 (1986).

105. See Blitz, supra note 101, at 1084-1105.

106. See, e.g., Paul Grossman et al., Mindfulness-Based Stress Reduction and Health Benefits: A Meta-Analysis, 57 J. Psychosomatic Res. 35, 35-43 (2004).

107. See, e.g., Lawrence O. Gostin \& Anna Garsia, Governing for Health As the World Grows Older: Healthy Lifespans in Aging Societies, 22 Elder L.J. 111, 112 (2014).

108. See id.

109. Cf. Kirk Seiler, Colorado's Pot Industry Looks To Move Past Stereotypes, NPR (Dec. 2, 2014 3:52 AM), http://www.npr.org/2014/12/02/367767955/colorados-potindustry-looks-to-move-past-stereotypes (discussing Colorado's legalization of marijuana resulted in marijuana becoming a billion-dollar business for the state).

110. Cf. John Kass, N.Y. Action Dooms Seller of 'Loosies', Chicago Trib. (Dec. 4, 2014 9:24 PM), http://www.chicagotribune.com/news/columnists/kass/ct-eric-garner-kass- 
With this proposal, the government would be able to collect tax on the sales of neuroenhancing pharmaceuticals, ${ }^{111}$ which would benefit the U.S. citizens in the long run.

Some might counter argue using the slippery slope argument"without paternalism, things go out of control," resulting in high frequency of abuses ${ }^{112}$-and that accessibility promotes use. ${ }^{113}$ However, despite the initial effect of spiking in uses after universal access of neuroenhancing pharmaceuticals, the market would likely reach equilibrium. ${ }^{114}$ This is commonly seen in the example of buying a new treadmill where that household would likely only use it often in the first three days, then leave it in the garage and not touch it again for a long time. ${ }^{115}$ On balance, this slippery slope counterargument is concededly a fairly strong argument.

Some might further counter argue that allowing universal access to neuroenhancing pharmaceuticals might lead to a lazy generation ${ }^{116}$ because they could afford to work less (and might take too much of the drugs). However, this is actually unlikely because most individuals who take neuroenhancing pharmaceuticals in the first place are overachievers rather than lazy folks. Furthermore, having more time on their hand does not necessarily lead to laziness; rather, they could be spending extra quality time with family and friends.

met-1205-20141205-column.html (discussing the government's loss of tax revenue to black market cigarette).

111. See generally Daniel Shaviro, An Economic and Political Look at Federalism in Taxation, 90 Mich. L. Rev. 895 (1992).

112. See, e.g., Nicolas Cornell, A Third Theory of Paternalism, 113 Mich. L. Rev.1295 (2015).

113. Cf. Lynda Jeanine Cochran et al., Leisure Programming for Baby Boomers 64 (2009) (discussing that "access promotes use" when programs are conveniently located).

114. But see, e.g., Miles K. Light et al., Market Size and Demand for Marijuana in Colorado, Colo. Dep't of Revenue (2014) (concluding that Colorado's legalization of cannabis has not had much of an effect on the prevalence of cannabis consumption). However, Colorado's legalization of cannabis was too recent, on Nov. 6, 2012, to see any equilibrium effect. See generally Colo. Const. amend. 64.

115. Cf. Jennifer Soong, 7 Habits of Highly Effective Exercisers, Fitness, http:// www.fitnessmagazine.com/workout/tips/habits-of-effective-exercisers/ (last visited Sept. 28, 2015) (discussing advices to stay motivated to work out every day, for example, on a treadmill).

116. See Jennifer Welsh, Caffeine Turns Hard Workers into Slackers, LiveScience (March 28, 2012 11:54 AM), http://www.livescience.com/19330-stimulants-hardworkers.html. 


\section{Application to Three Case Studies}

This Article proposes to allow each individual, either as an adult or as a parent of a minor, to self-regulate his/her or his/her children's use of neuroenhancing pharmaceuticals. ${ }^{117}$ Government efforts and funding should instead be focused on educating users on the side effects of neuroenhancers. ${ }^{118}$ There should be a strict prohibition against coercion and discrimination in the employment settings. ${ }^{119}$ With neuroenhancing internal devices, the FDA should defer to the medical professionals to determine whether an individual would benefit from such technology without much harm. ${ }^{120}$ This section applies this proposal to three case studies to explore the nuances of this proposal.

\section{In the Academic Settings}

Universities have recently debated whether to consider an individual's use of federally regulated pharmaceutical stimulants in an academic test setting, which violates the university honor code. ${ }^{121}$ This proposal suggests that there is no usage of neuroenhancing pharmaceuticals that should ever trigger an honor code violation. A benefit is that this proposal would remove the complication of assessing whether an individual has ADHD or a prescription. Some scenarios come to mind to test this proposal's boundaries.

\section{a. Case Study 1}

Hypothetically, there is a new expensive drug, which is quite effective in improving concentration. A school estimates that a third of its students can afford it and is using the drug. Thus, the school proposes to make using this drug an honor code violation.

Applying this proposal, the school's change in its honor code would be erroneous. Conversely, no change in the honor code would instead be unfair for the students of the school. ${ }^{122}$ Some would criticize that the school's regulating attempt of such drug would be violating the federal law of self-regulation and the federal law would trump the

117. See discussion, supra Part II.A.

118. Id.

119. Id.

120. Id.

121. Cf. Liz McLaughlin, Adderall: The Whole Story, ReeseNewsLab (Oct. 26, 2011, 9:01 AM), http://reesenews.org/2011/10/26/adderall-the-whole-story/19843/ (discussing Duke University's recent change in its honor code).

122. See discussion, supra Part II.A. 
school's regulation. ${ }^{123}$ But others would counter argue that even with self-regulation, the alternatives (i.e. other neuroenhancing pharmaceuticals) still exist for the students who cannot afford this new drug, such as caffeine or Adderall, to level the playing field. Some might even argue that some of those students cannot afford Adderall pills. However, caffeine through coffee or caffeine pills is extremely affordable, which would be the cheapest alternative.

\section{b. Case Study 2}

Hypothetically, there is another new drug that is quite effective in improving concentration. However, a school estimates that $10 \%$ of its students is allergic to and cannot use this drug. Thus, the school proposes to make using this drug an honor code violation.

Applying this proposal, the school's change in its honor code would be erroneous. Again, no change in the honor code would instead be unfair for the students of the school. This hypothetical can be expanded further, for example, about $5 \%$ of the students are allergic to and cannot take caffeine. It is more common to see a caffeine allergy but it is possible to be allergic to amphetamine, the active ingredient of Adderall. ${ }^{124}$

However, it is extremely rare to be allergic to the new drug, caffeine and amphetamine; thus, the alternatives would almost always exist. Furthermore, the amount of people with such specific allergies was so small to begin with that they should not deter the adoption of this proposal. Instead, the government should focus on targeting the mass population when deciding a regulation, rather than the few exceptions.

\section{In the Employment Settings: Case Study 3}

\begin{tabular}{|c|c|c|c|}
\hline Situation & Employee & Condition & $\begin{array}{l}\text { Billable } \\
\text { Hours } 25\end{array}$ \\
\hline 1 & \multirow{2}{*}{$\begin{array}{l}\text { Employee I } \\
\text { (with ADHD) }\end{array}$} & not taking neuroenhancer & 1400 \\
\hline 2 & & taking neuroenhancer & 2100 \\
\hline 3 & Employee II & not taking neuroenhancer & 1700 \\
\hline
\end{tabular}

123. A school policy still has to abide to the federal law, most likely through the preemption doctrine. See, e.g., Thomas W. Merrill, Symposium, Preemption and Institutional Choice, 102 Nw. U. L. Rev. 727 (2008); Caleb Nelson, Preemption, 86 Va. L. Rev. 225 (2000).

124. See Linton, supra note 5 , at 996.

125. These are arbitrary numbers as a different enhancer may give a different boost in billable hours. The billable hours represent the maximum hours such an employee can work yearly. 


\begin{tabular}{|l|l|l|l|}
\hline 4 & $\begin{array}{l}\text { (without } \\
\text { ADHD) }\end{array}$ & taking neuroenhancer & 2400 \\
\hline
\end{tabular}

Table 1. Whom should an employer hire?

Table 1 outlines a hypothetical scenario of whom an employer should hire, wherein the employee I who has ADHD can work 1400 billable hours not taking any neuroenhancer in Situation 1 and 2100 billable hours taking any neuroenhancer in Situation 2, and the employee II who does not have ADHD can work 1700 billable hours not taking any neuroenhancer in Situation 3 and 2400 billable hours taking any neuroenhancer in Situation 4.

In a survey of 17 people asking who they would hire if they were the employer, 15 people agree that an employer would hire employee II over employee I, ${ }^{126}$ although the real-life scenario would likely be between Situations 2 and 3 because only employee I with ADHD has access to Adderall or the like through prescription. Situation 1 is not common in real life because an employee with ADHD would likely want to take neuroenhancer to be competitive in the job market. Situation 4 is also not common because an employee without ADHD would unlikely have access to neuroenhancer to use on a regular basis.

Assuming that in this hypothetical, the employer does not have a problem with gathering such billable information, ${ }^{127}$ this Article's proposal would likely result in mostly Situations 2 and 4 with some individuals remaining in Situation 3. As mentioned above, a benefit of this proposal is that it would likely remove the complication of assessing whether an individual has ADHD and the employer would likely benefit overall. Regarding the proposed change in discrimination law, ${ }^{128}$ an employer would likely hire employee I between Situations 2 and 3 to avoid discrimination liability.

126. The survey was taken in Law and Neuroscience, taught by Francis X. Shen, at University of Minnesota Law School on Nov. 25, 2014. See generally Francis X. Shen, The Law and Neuroscience Bibliography: Navigating the Emerging Field of Neurolaw, 38 Int'1 J. Legal Info. 352, 352-53 (2010).

127. For example, a prospective employer can interview potential employees for this information given the employees have a record of how much they bill in the previous years.

128. See supra Part II.A. 


\section{Rebuttals to Common Counterarguments Against Self-Regulation}

\section{1. "Playing God," Unnatural and Human Integrity}

Some might argue that modifying a human's brain is "playing God" $" 129$ because it is "an ability often imputed to God." 130 The arguments can be either "this is not how God meant us to be," 131 or "this is not the way evolution intended us to be." 132 To frame this criticism in another way, the unnatural concern goes, "it's wrong because it's just not right, because it's not natural." 133 Some even argue that allowing neuroenhancement violates human integrity, that neuroenhancement is "inherently cheating or inherently violates the integrity of the endeavor." "134

These criticisms are rather overplayed with each new technological advancement. ${ }^{135}$ First, everything we do in life can be viewed as "playing God"-from building a house for shelter (rather than living in a natural cave) to drinking coffee (rather than eating cocoa),-what makes taking neuroenhancing pharmaceuticals different than building a house for shelter? "If there were an Adam and Eve, everything about the way we live today is different from how they lived." 136

Secondly, the evolution argument is based on a flawed assumption that natural selection has a goal, plan or direction for us, but the reality

129. Cecil A.J. Coady, Playing God, in Human Enhancement 155-80 (Julian Savulescu \& Nick Bostrom eds., 2009); see also John Harris, Enhancement Are a Moral Obligation, in Human Enhancement 133-34 (Julian Savulescu \& Nick Bostrom, eds., 2009) (briefly discussing the "playing god" objection).

130. Cf. Allen Buchannan \& Russell Powell, The Ethics of Synthetic Biology: Suggestions for a Comprehensive Approach, U.S. Presidential Comm'n for the Study of Bioethical Issues 4 (2010), available at https://bioethics.gov/sites/default/files/The-Ethics-of-SyntheticBiology-Suggestions-for-a-Comprehensive-Approach.pdf (discussing the "playing God" argument in synthetic biology).

131. Greely, Remarks, supra note 17, at 1153.

132. Id. at 1154 .

133. Id. at 1153. Greely calls this unnatural argument the "Yuck" factor. Id.

134. Id. at 1152 .

135. See, e.g., John H. Evans, Playing God?: Human Genetic Engineering and the Rationalization of Public Bioethical Debate (2002) (human genetic engineering); Ted Peters, Are we Playing God with Nanoenhancement, in Nanoethics: The Ethical and Social Implications of Nanotechnology 173-82 (Fritz Allhoff et al. eds., 2007) (nanotechnology); Buchannan \& Powell, supra note 130, at 4 (synthetic biology); Allen Verhey, "Playing God" and Invoking a Perspective, 20 J. Med. \& Phil. 347, 347-64 (1995) (argifood biotechnology).

136. Greely, Remarks, supra note 17, at 1154. 
is, it does not. ${ }^{137}$ "[W]e are not a fixed end of natural selection as to which any sort of interruption is wrong." 138

Third, the integrity argument assumes the rules must be set in a certain way, but the reality is that "[w]e tinker with rules regularly."139 Furthermore, it is not cheating if this proposal solves the unfairness problem and levels the playing field. ${ }^{140}$ The former solution must have been cheating if unfairness and uneven playing field persists. ${ }^{141}$

\section{Discrimination and Systemic Coercion Remain}

The proposed change in discrimination law ${ }^{142}$ would likely not change the landscape of employment hiring in Case Study 3. An employer would still likely hire employee II over employee I if both employees take enhancing pharmaceuticals (as shown in Situations 1 and 3 ), simply because employee II outputs higher billable hours. ${ }^{143}$

Furthermore, the prohibition against individual coercion via the proposed change in discrimination law does not itself prevent systemic coercion. Employers, for example, do not need to flat out say "you have to take enhancing pharmaceuticals, or else you will not get hired" but they can hire employees who take enhancing stimulants over those who do not.

This type of systemic coercion would likely continue to happen even in an outright ban against enhancing pharmaceuticals. What the government can do really is to regulate access to such pharmaceuticals. Further, what a regulation does is to discourage and make an unethical hiring practice illegal. The regulation itself could not cover all the possible "wink wink nudge nudge" situations like the current black market for Adderall. A systemic coercion problem itself is hard to be solved when it occurs "under the table." Nonetheless, employees may still establish a "pattern and practice" of discrimination case against such employer if enough discrimination cases occur. ${ }^{144}$

137. See id. ("[N]atural selection does not have a goal, plan, or direction.").

138. Id.

139. Id. at 1152 .

140. See supra Part II.C.1.

141. See supra Part I.B.2.

142. See supra Part II.A.

143. See supra Part II.B.2.

144. See Christine Tsang, Comment, Uncovering Systemic Discrimination: Allowing Individual Challenges to A "Pattern or Practice", 32 Yale L. \& Pol'y Rev. 319 (2013). 


\section{CONCLUSION}

A recent rise in abusing neuroenhancing pharmaceuticals without prescription, especially in academic settings, begs the question of whether and how regulations should be introduced to address neuroenhancement. The systemic fairness problem raises some concern. Some individuals have access to neuroenhancing pharmaceuticals when others do not. Furthermore, the fairness problem can cause coercion and discrimination when there is an unequal power dynamic, especially in the employment context. The fairness problem calls for a solution that guarantees accessibility to almost everyone to improve his/her cognitive functions.

This Article proposes to allow each individual, either as an adult or as a parent of a minor, to self-regulate his/her or his/her children's use of neuroenhancing pharmaceuticals. Government efforts and funding should instead be focused on educating users on the side effects of neuroenhancers. There should be a strict prohibition against coercion and discrimination in the employment settings. With neuroenhancing internal devices, the FDA should defer to the medical professionals to determine whether an individual would benefit from such technology without much harm.

There are three main arguments for this proposal. First, this proposal would likely solve the current systemic unfairness problem and level the playing field for individuals not having access to neuroenhancing pharmaceuticals. Second, this proposal would further promote individualism, which aligns well with our Constitution's guaranty of freedom. Third, this proposal would likely result in a positive net effect on the society at large, such as "smarter," less stressed and healthier people, more innovations, preserving healthcare resources, and ultimately benefiting the U.S. economy. 